$p$-ISSN 1693-9484, $e$-ISSN : 2621-8313

Majalah Ilmiah Bahari Jogja (MIBJ)

Vol. 17 No. 1, Februari 2019 (96-104)

DOI : $10.33489 /$ mibj.v17i1.202

(C) 2019 Akademi Maritim Yogyakarta

\title{
Peningkatan Keterampilan Taruna KPN Sebagai Operasional Shipper Atau Ekspedisi Dalam Proses Stuffing Di Media Peti Kemas
}

\author{
Ade Chandra K ${ }^{\mathbf{1}}$ \\ ${ }^{1}$ Akademi Maritim Yogyakarta, Jl. Magelang Km.4,4 Yogyakarta 55284, Indonesia \\ Coreresponding Author.E.mail:adepng11@gmail.com.Telp:085292372862
}

\begin{abstract}
Abstrak
Pembelajaran yang dilakukan dalam mencapai kompetensi calon shipper atau ekspedisi dalam proses stuffing di media peti kemas milik Akademi Maritim Yogyakarta di jurusan Ketatalaksanaan Pelayaran Niaga. Adapun tujuan dalam karya tulis ini adalah ketercapaian kompetensi atau dengan istilah ketuntasan dalam proses pembentukan calon bagian operasional digudang eksportir yang mampu melakukan stuffing. Metode yang digunakan berupa proses role play stuffing oleh taruna tingkat tiga semester lima dalam pembelajaran Manajemen Bongkar Muat dan Penumpukan di media petikemas milik Akademi Maritim Yogyakarta. Adapun strategi dalam pembelajaran yang diterapkan berupa skenario planning pembelajaran, organizing, actuating, dan controlling. Hasil yang dicapai mewujudkan tenaga kerja yang professional dibidang pelayaran khususnya dibidang ketatalaksanaan pelayaran niaga untuk calon operasional bongkar muat yang nantinya bekerja digudang eksportir. Setelah pembelajaran berupa role play dihasilkan kemampuan dari operasional shipper maupun ekspedisi yang menangani muatan dalam proses stuffing.
\end{abstract}

Kata kunci; keterampilan, operasional bongkar muat, stuffing

\section{ABSTRACT}

Learning is done in achieving the competency of prospective shipper or expedition in the stuffing process in container media owned by the Yogyakarta Maritime Academy in the Department of Commercial Shipping Management. The purpose of this paper is to achieve competence or with the term completeness in the process of forming prospective operational parts in the warehouse of exporters who are capable of stuffing. The method used was in the form of a role play stuffing process by the three-semester level cadets in learning Load and Stacking Management in container media owned by the Yogyakarta Maritime Academy. The strategies in learning that are applied are learning planning, organizing, actuating, and controlling scenarios. The results achieved to realize a professional workforce in the field of shipping, especially in the field of commercial shipping management for prospective loading and unloading operations that will work in the warehouse exporter. After learning in the form of role play, the ability of the shipper's operational and expedition is produced which handles the cargo in the stuffing process.

Keywords; skills, loading and unloading operations, stuffing 


\section{PENDAHULUAN}

Pemuatan cargo ke dalam peti kemas diperlukan keterampilan dari operasional petugas dari pihak shipper maupun ekspedisi dalam penggunaan alat dan bahan yang nantinya diterapkan di dalam ruangan petikemas. Ada yang berpendapat secara bisnis bahwa pemanfaatan ruangan muatan agar mampu diisi semaksimal mungkin agar efektifitas dan efisien penggunaan ruangan. Untuk menghasilkan calon para operasional tersebut perlunya dilakukan latihan secara real dalam proses stuffing. Peti kemas sebagaimana dikenal berbentuk persegi panjang terbuat dari bahan baja, dan difungsikan untuk menggudangkan barang yang diangkut moda transportasi di perairan, darat dan udara. Konstruksi petikemas yang memiliki karakteristik terbuat dari bahan baja yang mampu memikul beban hingga >30000 kilogram didukung dengan rangka baja dan pintu disisi sebelah belakang.

Prinsip dasar pengiriman barang dengan sistem angkutan peti kemas terbagi dua status yakni FCL dan LCL. Status FCL adalah status seluruh muatan satu unit peti kemas dimiliki satu pengirim dan satu penerima. Pengirim bertanggung jawab menyusun muatan ke dalam peti kemas dipelabuhan muat dan penerima bertanggung jawab mengeluarkan muatan dari peti kemas dipelabuhan bongkar.

General Cargo Container adalah Peti Kemas yang dipakai untuk mengangkut muatan umum (General Cargo). Peti kemas yang termasuk dalam general cargo adalah General purpose Container.

Distribusi menurut Herry Gunawan 2014 merupakan sambungan kunci antara produksi dan pemasaran yang akan meningkatkan profitabilitas bagi perusahaan. Adapun salah satu kegiatan dalam distribusi fisik yaitu berupa pengemasan dimana melibatkan pengemasan volume besar, mempalaet, kontainerisasi dan segala macam pengemasan untuk distribusi yang aman dan ekonomis.

Freightforwarder adalah lembaga jasa pengurusan trasportasi yang mengkoordinasikan angkutan multimodal sehingga terselenggara angkutan terpadu sejak dari door shipper sampai door consignee.

Salah satunya peranan Freightforwarder menurut Roseline 1989 adalah membantu pemilik barang agar semua ketentuan perdagangan luar negeri dan memberikan saran dalam hal pengepakan yang murah, aman, dan efisien.

Stuffing merupakan proses penataan barang yang sudah dipacking ke dalam container dengan memberikan kode yang sudah ditentukan dalam shipping mark dan di hitung untuk dasar pembuatan packing list dan invoice. Kelancaran pemuatan peti kemas ke kapal dapat dipengaruhi oleh banyak faktor (Thoni,Adi,Hardjono) antara lain:

1. Kelancaran kegiatan operasional depo peti kemas khususnya stuffing dalam untuk meningkatkan pendapatan dan kepuasan pengguna jasa.

2. Kurang kerjasama antara operasional depo dengan pihak EMKL mengakibatkan pemuatan peti kemas ke kapal terhambat.

3. Tenaga Kerja Bongkar Muat (TKBM) sangat mempengaruhi kelancaran dalam setiap penanganan pergerakan peti kemas.

4. Ekspedisi Muatan Kapal Laut (EMKL) melakukan kegiatan stuffing dalam tidak maksimal sangat mempengaruhi kelancaran dalam penanganan pergerakan peti kemas. 
5. Keterlambatan trucking atau trailer pengangkutan dalam pekerjaan lift on/lift off di lapangan depo peti kemas. Hal ini dapat menimbulkan kemacetan sehingga tidak optimalnya kapasitas lapangan penumpukan.

6. Dokumen masih birokrasi dan perijinan kadang-kadang menyebabkan terjadinya keterlambatan dokumen.

7. Kelancaran stuffing dan stripping akan meningkatkan pendapatan dan kepuasan pengguna jasa.

8. Cuaca hujan akan mengahambat pekerjaan bongkar muat barang, sehingga menghambat juga terhadap kelancaran pemuatan peti kemas ke kapal

Faktor-faktor Yang Mempengaruhi Kelancaran Pemuatan Peti Kemas di Depo Peti Kemas :

1. Kapasitas lapangan penumpukan di depo peti kemas terbatas akhirnya para EMKL akan melakukan stuffing dalam kurang maksimal

2. Koordinasi bagian operasional lapangan sangat dibutuhkan kerja samanya khususnya antara foreman bongkar muat dengan foreman stuffing/stripping dan juga para EMKL.

3. Tenaga Kerja Bongkar Muat (TKBM) akan sangat mempengaruhi kelancaran dalam setiap penanganan pergerakan peti kemas.

4. Keterlambatan trucking atau trailer pengangkutan dalam pekerjaan lift on/lift off di lapangan depo peti kemas. Hal ini dapat menimbulkan kemacetan sehingga tidak optimalnya kapasitas lapangan penumpukan.

5. Dokumen masih birokrasi dan perijinan kadang-kadang menyebabkan terjadinya keterlambatan dokumen.

6. Alat bongkar muat seperti forklift dan Reach Stacker (RS).

Faktor-Faktor Menghambat yang Menjadi Kendala Kegiatan Pemuatan Peti

Kemas ke Kapal di Depo Peti Kemas :

1. Tidak optimalnya stuffing dalam Proses stuffing dalam yang tidak optimal sangat berpengaruh besar bagi kelancaran kegiatan operasional depo peti kemas khususnya pemuatan peti kemas ke kapal dan bagi kelancaran operasional alat mekanis (reach stacker).

2. Konsistensi EMKL Konsistensi EMKL dalam penyelesaian proses stuffing dalam sering terjadi kurang maksimal. Oleh karena itu konsistensi dari EMKL dalam penyelesaian proses stuffing dalam merupakan penunjang dalam kelancaran pemuatan peti kemas ke kapal.

3. Petugas (kerani) stuffing Kesalahan operasional yang sering dilakukan oleh kerani stuffing, mengakibatkan kebiasaan buruk EMKL menjadi tidak terkontrol. Kesalahan operasional kerani stuffing yang sering mereka lakukan adalah dengan memberikan hamparan peti kemas di luar area blok hamparan atau di luar batas maksimum ground slot yang telah ditentukan, tanpa berkoordinasi terlebih dahulu dengan foreman stuffing/stripping.

4. TKBM (Tenaga Kerja Bongkar Muat) Kurangnya bimbingan dan sosialisasi dari kepala TKBM sangat berpengaruh bagi kinerja buruh. Bimbingan juga merupakan faktor yang sangat penting bagi buruh.

5. Karena Alam/Cuaca Hujan akan menghambat proses stuffing dalam, khususnya pada barang karungan (Beras, Pupuk, Gandum). 
6. Pengurusan Dokumen Karena masih birokrasi dan perijinan terkadang menyebabkan terjadinya keterlambatan dokumen, sehingga proses stuffing dalam yang akan dilakukan menjadi tidak sesuai dengan yang direncanakan.

7. Kurangnya kerjasama antara bagian operasional lapangan dengan pihak EMKL atau kurangnya koordinasi.

8. Nomor booking dikarenakan shipper akan menambah booking tanpa menghubungi CS terlebih dahulu, CS belum mengeluarkan nomor booking tambahan yang diorder oleh shipper.

9. Inpeksi peti kemas tidak dapat dilaksanakan secara akurat dikarenakan sarana dan prasarana kurang memadai dan SDM terbatas

10. Adanya para EMKL melakukan kecurangan terhadap sesama para EMKL dalam pemilihan peti kemas, akhirnya mengakibatkan pertengkaran sesama EMKL, ini disebabkan karena kurangnya koordinasi terhadap petugas lapangan penumpukan atau kerani stuffing.

11. Daftar pemuatan peti kemas ke kapal yang tidak sesuai dengan daftar muat atau di luar daftar pemuatan akhirnya mengakibatkan pencarian peti kemas dan waktu tunggu yang lama.

Langkah pihak bagian operasional depo peti kemas kepada EMKL Untuk mengoptimalkan stuffing dalam:

1. Pendekatan kepada EMKL sebagai langkah awal untuk menimbulkan rasa saling membutuhkan.

2. Melakukan briefing kepada kerani stuffing untuk lebih meningkatkan kinerjanya serta penanaman rasa tanggung jawab pada tugas masing- masing, dan menekankan kepada kerani stuffing untuk melakukan monitoring container terkait proses hampar peti kemas terhadap stok ground slot, serta pengawasan terhadap kegiatan stuffing dalam lebih diperketat, supaya tidak terjadi penyalahgunaan penggunaan peti kemas.

3. Menekan kinerja TKBM diantaranya adalah

a. Mengontrol dan mengecek kesiapan TKBM.

b. Memberlakukan sistem borongan kerja.

c. Menekan produktivitas buruh dengan dasar penentuan target (37 box dicapai oleh 18 orang buruh).

d. Secara berkala melakukan pelatihan-pelatihan, sehingga ketika proses stuffing dalam berlangsung para buruh sudah siap dan terampil dalam kegiatan stuffing dalam.

e. Seharusnya ada suatu peraturan yang mengatur tentang kewenangan PBM terhadap buruh secara langsung, sehingga dalam proses stuffing dalam, jika terjadi suatu kesalahan atau kekeliruan, PBM mempunyai kewenangan menegur atau memberi sanksi terhadap buruh.

f. Kepala buruh dalam melayani buruh dari PBM harus konsekuen dengan jumlah buruh yang diminta, sehingga tidak ada yang merasa dirugikan.

4. Selalu memperhitungkan waktu proses stuffing dalam dengan kondisi cuaca yang terjadi pada saat bekerja, misalnya jika kondisi cuaca tidak mendukung seperti hujan, secara otomatis proses pengisian barang ke dalam peti kemas (stuffing) akan dihentikan untuk sementara waktu. 
5. Lebih dimudahkan dan dipercepat dalam pengurusan dokumen terhadap pihak EMKL.

Usaha-Usaha Depo Peti Kemas Untuk Mengatasi Hambatan-Hambatan Jalannya Pemuatan Peti Kemas ke Kapal

1. Kepala depo peti kemas sering-sering koordinasi dengan petugas lapangan untuk merencanakan dan memastikan kebutuhan alat angkat atau angkut mekanis agar kegiatan di depo peti kemas dapat berjalan lancar, untuk rencana melihat kegiatan kapal, untuk memastikan pihak koordinator melakukan komunikasi dengan operator alat angkat atau angkut mekanis.

2. Melakukan identifikasi jumlah bongkar kapal dengan melakukan komunikasi verbal bersama foreman B/M PBM dan marine operasional pelayaran agar dapat ditentukan alokasi stack peti kemas sesuai tujuan.

3. Memastikan permintaan muatan peti kemas ke luar depo peti kemas dengan melakukan koordinasi bersama foreman B/M PBM marine operasional pelayaran agar proses muat kapal berjalan sesuai dengan target $\mathrm{B} / \mathrm{M}$ yang telah ditentukan.

\section{METODE}

Adapun tempat pelaksanaan role play di Unit Peti kemas milik Akademi Maritim Yogyakarta yang beralamat di Jl. Magelang KM. 4,4 dusun Mesan Sinduadi Mlati Sleman Yogyakarta 55284

Sedangkan untuk waktu pelaksanaan pembelajaran yaitu pada tahun kalender akademik 2018/2019 pada jurusan Nautika Semester 3.

Untuk peralatan yang di gunakan yaitu peti kemas, Alat Pelindung Diri, Pallet, karpet, Rachet lashing

Pembekalan teori dan alur praktek yang dilakukan adalah sebagai berikut: Skenario Pembelajaran (bermain peran) - kelompok kerja (penetapan bermain peran) - simulasi

Adapun pengumpulan data yang dilakukan yaitu dengan mengumpulkan informasi dan data dengan bantuan berbagai macam material yang ada di perpustakaan seperti dokumen, buku, catatan, majalah, kisah-kisah sejarah dan sebagainya.

\section{HASIL DAN PEMBAHASAN}

Usaha meningkatkan kemampuan kerja Taruna Akademi Maritim Yogyakarta pada program studi Ketatalaksanaan Pelayaran Niaga pada ranah keterampilan dalam hal ini ranah psikomotorik sebagai tujuan pembelajaran. Dengan cara membimbing serta memfasilitasi para taruna Akademi Maritim Yogyakarta yang nantinya menjadi praktisi atau operasional sebagai Shipper maupun Ekspedisi. Pembimbingan ketrampilan secara real berupa media peti kemas, bahan dan alat yang real terkait dalam pengerjaan stuffing muatan ke dalam peti kemas.

Stuffing adalah pengepakan barang yang dilakukan ke dalam container, Para ahli menyimpulkan stuffing adalah suatu kegiatan yang dilakukan untuk 
memindahkan suatu barang dalam container atau memasukan barang dari luar container ke dalam container.

Dalam proses stuffing sebelum mengisi peti kemas Operator peti kemas tentunya akan memeriksa keadaan peti kemas sebelum mengisinya. Ada kemungkinan bahwa peti kemas sampai kepadanya dari consignee terakhir, yang melihat isi dan keadaan peti kemas secara keseluruhan.

Pemeriksaaan peti kemas dimana muatan haruslah di pak dan diamankan di dalam peti kemas. Peti kemas haruslah diperiksa baik bagian dalam maupun bagian luar sebelum diisi muatan. Petikemas yang rusak dapat menimbulkan bencana terhadap orang-orang yang mengurus atau mengangkutnya. Jika suatu peti kemas terlihat sangat rusak maka pelaksana peti kemas haruslah dihubungi untuk memperoleh penggantian.

\section{PELAKSANAAN}

\section{SKENARIO 1}

Memberi karpet atau tiker pada dasar peti kemas

Bahan yang digunakan:

1. Matras

2. Pallet

3 Mebel

4 Peti

KASUS:

Memasang alas pada lantai peti kemas sebagai pelindung antar muatan dan body peti kemas

1. Membuka pintu petikemas

Setelah instruktur memberikan briefing dan contoh maka taruna melakukan packing muatan dengan memasang perlindungan muatan dengan bahan berupa kardus, karpet dan sebagainya. Packing tersebut dilakukan di dalam peti kemas atau diluar peti kemas. Muatan mebel berupa kursi dilapisi kardus bagian bodynya dengan diikat dengan menggunakan tali rafia. Untuk muatan berupa meja bilyar dilakukan packing sekaligus sebagai pelinding atau dunnage digunakan karpet yang dipasang setelah meja bilyar berada di dalam kontainer. Langkah selanjutnya yang dilakukan yaitu membawa muatan ke depan pintu petikemas dan dilakukan proses membuka pintu petikemas. Operasional meletakkan alas atau matras dan pallet pada dasar peti kemas sebagai landasan muatan.

Stuffing muatan ke dalam peti kemas berdasarkan daftar packing list dilakukan di gudang eksportir dalam hal ini dilakukan oleh taruna yang bertindak sebagai shipper/ekspedisi.

Membuka pintu peti kemas yaitu dengan menarik bersamaan kedua pintu peti kemas tersebut sampai terbuka. Memasang alas berupa matras atau tiker sebagai landasan sebelum meletakkan mebel yang telah di packing dan muatan dengan kemasan peti.

Langkah selanjutnya taruna memasukkan muatan mebel yang sudah diberi perlindungan atau lapisan packing dan barang tersebut sesuai dengan packing list.

2. Memasang lashing peti kemas 
Menurut Permen Perhubungan Republik Indonesia No 115 tahun 2016 tentang tata cara pengangkutan kendaraan diatas kapal bahwa lashing gear adalah semua alat baik yang terpasang permanen atau alat-alat yang dapat dipindahpindah, yang digunakan untuk mengikat dan mendukung unit-unit muatan

\section{Dua jenis Ratchet Tie Down yaitu model pompa dan model tarik.}

\section{Model pompa}

Untuk menggunakan tie down model ini, posisikan terlebih dahulu pengaitnya dengan posisi tali yang belum dijadikan satu. Setelah menemukan posisi pengait yang pas, baru tali yang panjang dimasukkan pada lubang yang ada di perangkat pengunci.

Tarik talinya lebih dulu, baru kemudian pompa pengunci tie down. Apabila menggunakan 2 buah ratchet, setelah satu sisi terpasang, jangan diikat terlalu kencang terlebih dahulu. Setelah posisi kiri dan kanan sudah terikat tie down, baru kencangkan secara bergantian sampai dirasa cukup.

Untuk melepas atau merenggangkan kekecangan tali pengikat, caranya dengan tarik pengait yang ada pada bagian ratchet yang untuk memompa. Lalu luruskan posisi perangkat besi pengikat dan baru deh tali pengikat bisa dilepas atau dikendurkan.

\section{Model tarik}

Lanjut ke tie down model tarik yang dianggap lebih praktis, pasalnya untuk mengencangkan tinggal tarik saja. "Lantaran tinggal tarik, maka posisi tali pengikat yang pendek dan ada besi penguncinya, ada di atas. Itu agar gampang saat posisi menarik talinya.

Mengencangkan tali tinggal tarik, sedangkan untuk melepas atau mengendurkan tali dengan memencet bagian depan dari besi pengikat. Sayangnya butuh pembantu buat memastikan posisi motor, agar lebih mudah memasang tie down model tarik.

Kemungkinan mengikat muatan menurut RP Suyono dalam peti kemas:

a. Lantai kayu dalam peti kemas: mengikat dengan stoppor kayu dan papan yang dipaku di lantai

b. Dinding bagian dalam: penahan barang-barang ringan

c. Corner post: dapat dipakai untuk menopang muatan

d. Bull rings dan lashing bars: titik topang untuk tali pengikat, kawat, rantai dan sebagainya

Muatan yang diikatkan pada tupai-tupai atau mata rantai yang disediakan haruslah dalam keadaan baik dan tertancap baik.

Alat/Bahan yang digunakan dalam proses lashingan ini yaitu ratchet lashing

Kasus:

Muatan masuk dalam peti kemas dan diikatkan

Pelaksanaan:

Instruktur memberikan briefing dan memberikan contoh penggunaan ratchet lashing dan taruna menerapkan dengan mengikat muatan tersebut di dalam peti kemas 
Proses Lashing muatan saat proses stuffing

1. Taruna mengisi muatan mebel dan muatan dengan kemasan peti ke dalam peti kemas sesuai dengan terdapat pada packing list.

2. Taruna melakukan lashing muatan peti dengan menggunakan ratchet lashing dengan mengaitkan ratchet pada pengait yang tersedia pada dinding peti kemas..

3. Proses lashing muatan di dalam peti kemas dengan menggunakan ratchet lashing. Lashing yang dilakukan taruna dengan menggunakan ratchet untuk mengencangkan mebel dan muatan dengan kemasan peti diikatkan dengan kencang di dalam peti kemas. Memposisikan muatan didalam peti kemas sepadat mingkin dengan memperhatikan lapisan pelindung masing-masing muatan. Setelah ditempatkan selanjutnya dilakukan pengikatan. Untuk muatan berupa kursi atau mebel dilakukan dengan melilitkan ratcet pada kursi, dan bila menggunakan pallet dilakukan lilitan untuk lebih mengikat kencang muatan tersebut. Sedangkan untuk muatan meja bilyar untuk menjaga agar muatan tidak bergeser juga dapat dilakukan pengikatan menggunakan ratchet lashing, karena akibat goncangan muatan muatan berat akan bergeser dan merusak muatan yang memiliki kemasan yang tidak keras.

Daftar barang dalam kemasan adalah rincian barang yang ditempatkan pada setiap kemasan, pembungkus, peti atau karung. Rincian barang meliputi jenis barang, nomor kode, jumlah, isi setiap peti kemas, ukuran, berat kotor persatuan; termasuk juga merk, kode penomoran, dan metode pengemasan.

\section{SIMPULAN}

Transfer ilmu dari instruktur ke taruna dapat dilakukan dengan berbagai metode pembelajaran. Strategi Roleplay merupakan salah satu teknik transfer ilmu dengan ketercapaian ranah kognitif, afektif dan psikomotorik. Dengan melakukan langsung secara real didukung dengan alat dan bahan yang dimiliki akan berdampak pada ketercapaian keterampilan dari taruna akan proses stuffing yang dilakukan oleh operasional shipper atau operasional ekspedisi.

Peningkatan kompetensi taruna KPN sebagai operasional Shipper dapat dilakukan melalui metode pembelajaran role play dengan mengimplementasikan skenario sesuai kondisi di lapangan.

\section{DAFTAR PUSTAKA}

Amir, M.S (1997). Peti Kemas Masalah dan Aplikasinya, PT Pustaka Binaman :Pressindo

D.A Lasse, (2015). Manajemen Bisnis Trasnportasi Laut Charter dan Klaim, STMT Trisakti: Raja Grafindo Persada Jakarta

D.A Lasse, (2012). Manajemen Muatan, aktivitas Rantai Pasok di area Pelabuhan: PT Raja Grafindo Persada, Jakarta

Engkos Kosasih dan Hananto Soewondo, (2007). Manajemen Perusahaan Pelayaran sesuatu pendekatan praktis dalam bidang usaha pelayaran: STMT, PT. RajaGrafindo Persada, Jakarta 
Herry Gunawan, (2014). Pengantar Transportasi dan Logistik: STMT RajaGrafindo Persada, Jakarta

Peraturan Menteri Perhubungan Republik Indonesia No 115 tahun 2016 tentang tata cara pengangkutan kendaraan diatas kapal

Roselyne Hutabarat, (1989). Transaksi Ekspor Import, Erlangga, Jakarta

RP Suyono, (2007). Shipping Pengangkutan Intemodal Ekspor Impor melalui laut,: PPM, Jakarta

Thni M, Adi Purwanto,Hardjono, (2012). Optimalisasi Stuffing Terhadap Kelancaran Pemuatan Peti Kemas, UHT, Surabaya, Jurnal Aplikasi Pelayaran dan Kepelabuhanan, Volume 1 Nomor 1, 2012

https://www.arthanugraha.com/mengenal-peti-kemas-kontainer/ http://www.definisimenurutparaahli.com/pengertian-studi-pustaka/ https://www.slideshare.net/jibrinaddifia/vol3-no1-optimalisasi-stuffing-dalamterhadap-kelancaran-pemuatan-peti-kemas-thni-madi-purwantohardjono https://rianjayasafety.com/cara-pemasangan-ratchet-tie-down/ 